\title{
Lactic acid: not just a waste product?
}

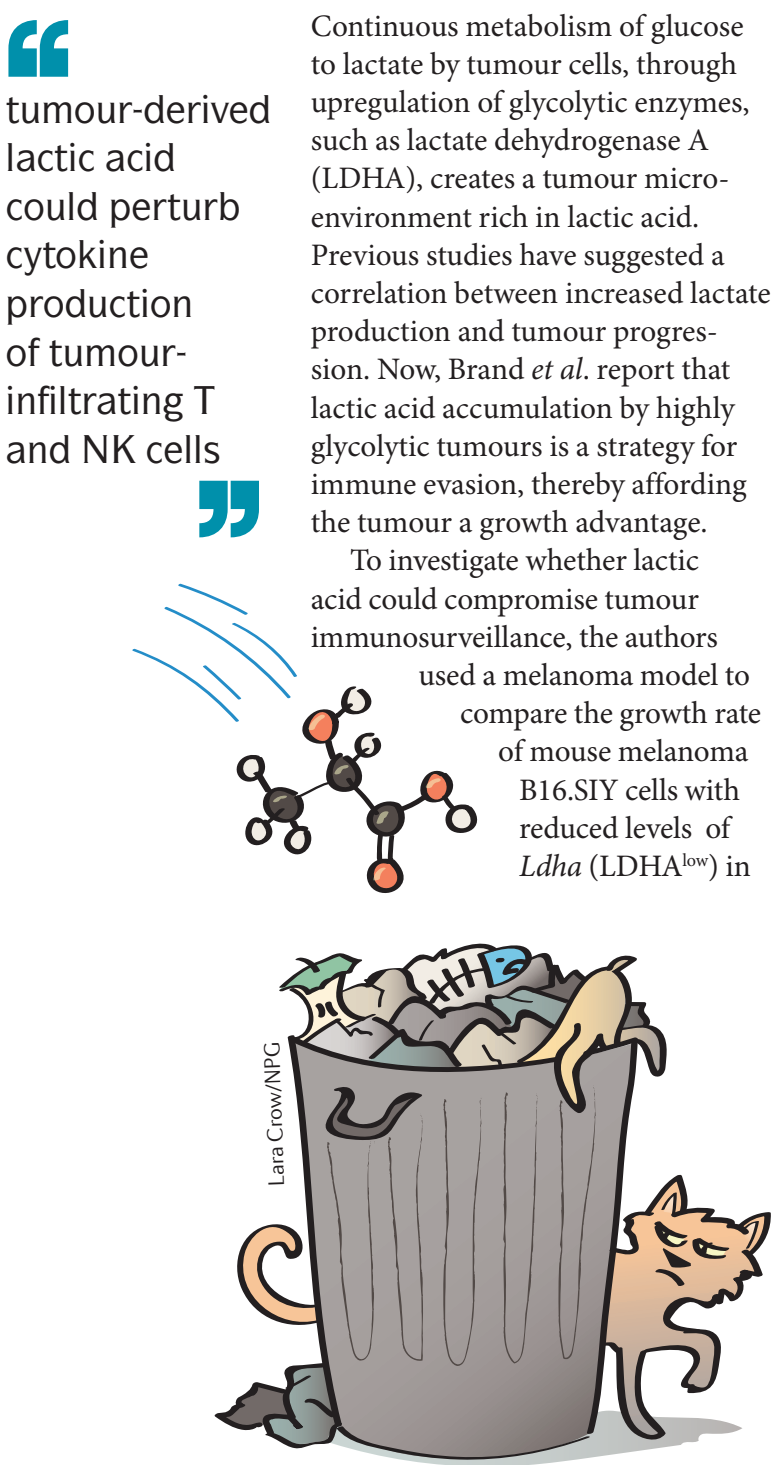

immunocompetent $(\mathrm{C} 57 \mathrm{BL} / 6)$ versus immunodeficient $\left(\operatorname{Rag} 2^{-/ \gamma} \mathrm{C}^{-/}\right)$mice. LDHA $^{\text {low }}$ tumours, which secreted less lactate, grew at a slower rate and with increased infiltration of $\mathrm{T}$ cells and natural killer (NK) cells in immunocompetent mice than those of control tumours (formed from B16.SIY cells with comparatively higher levels of Ldha expressed). By contrast, in Rag $2^{-/ \gamma} \mathrm{cc}^{-/-}$mice, which lack B, T and NK cells, LDHA ${ }^{\text {low }}$ and control tumours developed at the same rate, indicating that immune cell infiltration in $\mathrm{LDHA}^{\text {low }}$ tumours is effective at limiting tumour expansion. Interestingly, this effect of tumour-induced lactic acid production on the immune cell balance seems to be restricted to the local tumour environment as the composition of immune cells in the blood and spleen of LDHA $^{\text {low }}$ tumour-bearing mice was unchanged.

Brand et al. identified the tumour immune infiltrate in $\mathrm{LDHA}^{\text {low }}$ tumours as containing a higher proportion of $\mathrm{CD}^{+} \mathrm{T}$ cells and NK cells, with both effector cell types expressing increased levels of interferon- $\gamma$ (IFN- $\gamma$, encoded by Ifng). Moreover, IFN- $\gamma$ production was necessary for the control of $\mathrm{LDHA}^{\text {low }}$ tumour volume, as the growth difference between control and LDHA low tumours was lost in Ifng ${ }^{-1-}$ mice. To establish the mechanism by which tumour-derived lactic acid could perturb cytokine production of tumour-infiltrating $\mathrm{T}$ and NK cells, the authors incubated CD8 ${ }^{+} \mathrm{T}$ cells in the presence of ${ }^{13} \mathrm{C}_{1}$-labelled lactate and hydrochloric acid $(\mathrm{HCl})$ to replicate conditions of high lactic acid in the tumour microenvironment. This experiment revealed that lactic acid uptake was sufficient to cause intracellular acidification and suppress expression of nuclear factor of activated T cells (NFAT), a regulator of IFNG gene expression during $\mathrm{T}$ and NK cell activation.

Finally, the authors related their mouse findings to human melanoma data by analysing a cohort of 44 patients with metastatic melanoma and showed that LDHA expression negatively correlated with survival. Furthermore, biopsy samples from cutaneous melanoma metastases were found to have higher lactate levels with fewer activated $\mathrm{T}$ cells than those of normal skin. In summary, this work highlights how LDHA-mediated lactic acid can be used by a tumour as an immunosuppressive metabolite to induce immune tolerance and promote tumour growth.

Anna Dart

ORIGINAL ARTICLE Brand, A. et al. LDHAassociated lactic acid production blunts tumor immunosurveillance by T and NK cells. Cell Metab. https://dx.doi.org/10.1016/j.cmet.2016.08.011 (2016) 